\title{
Ethnicity and social deprivation independently influence metabolic control in children with type 1 diabetes
}

\author{
P. J. Carter • W. S. Cutfield • P. L. Hofman • \\ A. J. Gunn • D. A. Wilson • P. W. Reed • C. Jefferies
}

Received: 25 March 2008 / Accepted: 19 June 2008 / Published online: 5 August 2008

(C) Springer-Verlag 2008

\begin{abstract}
Aims/hypothesis This study was performed to evaluate the influence of ethnicity and socioeconomic status (SES) on metabolic control in a population-based cohort of children with type 1 diabetes mellitus, and to evaluate whether any relationship between ethnicity and $\mathrm{HbA}_{1 \mathrm{c}}$ is mediated by SES. Methods We performed a retrospective review of all patients under age 16 years with type 1 diabetes $(n=555)$ from 1995 to 2005 in the greater Auckland region, New Zealand. Diabetes care variables and $\mathrm{HbA}_{1 \mathrm{c}}$ values were collected prospectively, during clinic visits.

Results The mean population $\mathrm{HbA}_{1 \mathrm{c}}$ was $8.3 \pm 1.3 \%$. Maori and Pacific patients had poorer metabolic control than their European counterparts $(9.1 \%$ and $9.3 \%$ vs $8.1 \%, p<0.001)$ and higher rates of moderate to severe hypoglycaemia (31.1 and 24.8 vs 14.9 events/100 patient-years, $p=0.03$ ). In multiple linear regression analysis, both ethnicity and SES were independently associated with $\mathrm{HbA}_{1 \mathrm{c}}(p<0.001)$. Other factors associated with higher $\mathrm{HbA}_{1 \mathrm{c}}$ level were longer duration of diabetes, higher insulin dose, lower BMI $z$ score and less frequent blood glucose monitoring $(p<0.001)$.
\end{abstract}

\footnotetext{
P. J. Carter · W. S. Cutfield - P. L. Hofman • A. J. Gunn •

D. A. Wilson $\cdot$ P. W. Reed $\cdot$ C. Jefferies $(\square)$

Paediatric Diabetes Service, Greenlane Clinical Centre,

Starship Children's Health,

Level 4, Building 15,

Private Bag 92024 Auckland, New Zealand

e-mail: craigj@adhb.govt.nz

P. J. Carter • W. S. Cutfield • P. L. Hofman • D. A. Wilson •

C. Jefferies

Liggins Institute,

Auckland, New Zealand
}

A. J. Gunn

Department of Physiology, University of Auckland,

Auckland, New Zealand
Conclusions/interpretation Both ethnicity and SES independently influenced metabolic control in a large, unselected population of children with type 1 diabetes. Irrespective of SES, Maori and Pacific youth with type 1 diabetes were at greater risk of both moderate to severe hypoglycaemia and long-term complications associated with poor metabolic control.

Keywords Adolescent $\cdot$ Child $\cdot$ Ethnicity $\cdot \mathrm{HbA}_{1 \mathrm{c}}$. Hypoglycaemia · Metabolic control - Socioeconomic status . Type 1 diabetes

$\begin{array}{ll}\text { Abbreviations } \\ \text { NCNS } & \begin{array}{l}\text { New Zealand National Children's Nutrition } \\ \text { Survey }\end{array} \\ \text { NZDep01 } & \begin{array}{l}\text { New Zealand Index of Deprivation } 2001 \\ \text { SES }\end{array} \\ \text { socioeconomic status }\end{array}$

\section{Introduction}

Ethnicity and socioeconomic status (SES) are well-established and closely linked risk factors for a range of health outcomes [1]. Determining the relative contribution of cultural influences on health vs the fundamental fiscal ability to access and use necessary healthcare has proved difficult. Several studies from the USA [2-4] and UK [5] have indicated that SES and affluence, rather than ethnicity, primarily mediate the effect on health outcomes. Evidence from New Zealand suggests that inequalities in health persist even after adjusting for deprivation [6]; likely due to multiple factors, including differences in health-risk behaviours such as smoking rates [7] and institutional or interpersonal discrimination [6].

In type 1 diabetes, optimal metabolic control, as reflected by lower $\mathrm{HbA}_{1 \mathrm{c}}$ levels, is vital to reduce the risk 
of long-term complications $[8,9]$. Although data in childhood are limited, poor metabolic control tracks through adolescence and, in turn, $\mathrm{HbA}_{1 \mathrm{c}}$ in adolescence is strongly correlated with later adult diabetes-related outcome [1012]. Cross-sectional studies typically show that children of ethnic minorities have higher $\mathrm{HbA}_{1 \mathrm{c}}$ levels [13-16]. However, it remains unclear whether this poorer metabolic control is independent of SES, and many of the studies examined selected cohorts that may not be representative of the general population [2, 17-19].

New Zealand has a population of 4 million people, the majority of whom are of European descent. Auckland, the largest city in New Zealand, is the most ethnically diverse, with approximately $11 \%$ of people identifying as indigenous Maori, $14 \%$ as Pacific and $19 \%$ as Asian [20]. By international standards, the incidence of type 1 diabetes in young New Zealanders is moderate at 17.9 per 100,000 , with lower rates reported for Maori and Pacific young people than for Europeans [21]. However, Maori and Pacific youth have been shown to have poorer outcomes in several key health areas [22, 23]. The 2002 New Zealand National Children's Nutrition Survey (NCNS) identified ethnic and socioeconomic differences in diet and activity that could be expected to affect diabetes control, but did not examine the relationship between ethnicity and socioeconomic factors [24].

Starship Children's Health provides specialist care for all children diagnosed with type 1 diabetes in the Auckland region, with case ascertainment levels of over 95\% [21]. The purpose of this study was to examine factors affecting metabolic control in this population of children with type 1 diabetes, and, in particular, whether any effect of ethnicity on $\mathrm{HbA}_{1 \mathrm{c}}$ is mediated by SES. New Zealand has a social security system that provides medical care free of charge, meaning that the direct costs of type 1 diabetes to patients' families are minimal. Thus, income should not directly distort take-up of care.

\section{Methods}

Setting and sample

All children or adolescents with type 1 diabetes who attended the Pediatric Diabetes service at Starship Children's Health (Auckland, New Zealand) between 1 January 1995 and 31 December 2005 were eligible for this study. Clinical and demographic data, including $\mathrm{HbA}_{1 \mathrm{c}}$, selfreported frequency of blood glucose self-monitoring, insulin dose, number of insulin injections per day, hypoglycaemic events and BMI, were prospectively recorded on all patients at each outpatient visit. Ethics approval for the use of this data was obtained from the Northern X Regional
Ethics Committee. Of 562 eligible patients, no SES data were available for seven children (six European and one 'other' ethnicity). Thus, the study population included 555 participants with a total of 6,518 clinic visits.

Clinic setting The Paediatric Diabetes Service at Starship Children's Health provides centralised medical care for all diabetic children up to 15 years of age who reside in the Auckland region, drawing from a population of approximately 1.3 million [20]. Children were routinely seen every 3 months and more frequently if they had poor glycaemic control.

\section{Measures}

Type 1 diabetes was diagnosed based on clinical features, such as ketoacidosis, ongoing requirement for insulin, and by detection of antibodies to glutamic acid decarboxylase, islet antigen 2, islet cell or insulin autoantibodies. Insulin pump therapy began in 2004 and only 17 participants were using insulin pumps by the end of 2005. Therefore, only data relating to intermittent injection therapy were included for these participants. Similarly, as only 21 participants had diabetes for greater than 12 years, data for these individuals were truncated at 12 years duration.

Ethnicity Ethnicity recorded was by self-report using a prioritised system, such that if multiple ethnicities were selected, the patient was assigned to a single category, following an hierarchical classification of Maori, Pacific, Other and then European [25]. Those participants described as Other were predominantly of Indian or South-East Asian origin; there were small numbers of African, Middle Eastern and other ethnicities.

SES SES was classified using the New Zealand Index of Deprivation 2001 (NZDep01). This uses household census data reflecting nine aspects of material and social deprivation to divide New Zealand into tenths (scored 1-10) by residential address. Scores are derived from units covering a small area, each reflecting approximately 90 people [26]. To simplify analysis, scores were collapsed into quintiles (I-V), with quintile I indicating that the household is in the least deprived and quintile $\mathrm{V}$ in the most deprived $20 \%$ of areas in New Zealand.

Clinical measurements $\mathrm{HbA}_{1 \mathrm{c}}$ was measured by DCA 2000 Analyzer (Bayer, Elkhart, IN), which was standardised to laboratory-tested $\mathrm{HbA}_{1 \mathrm{c}}$ on a monthly basis. Height was measured to the nearest $0.1 \mathrm{~cm}$ using a wall-mounted Harpenden stadiometer (Holtain, Crosswell, UK). Weight was measured to the nearest $0.1 \mathrm{~kg}$, with the participant in 
light clothing, by electronic scales. BMI $z$ scores were calculated in accordance with the 2000 Centers for Disease Control and Prevention growth charts [27]. For patients younger than 2 years old, weight-for-length $z$ scores were calculated rather than BMI [27]. Episodes of moderate to severe hypoglycaemia were defined as (1) decreased level of consciousness as indicated by the need for assistance from others and/or (2) seizures [28]. The rate of hypoglycaemia for each patient was calculated as the total number of episodes of hypoglycaemia divided by length of followup, expressed per 100 patient-years.

\section{Data analysis}

ANOVA (with the nonparametric Kruskal-Wallis test used for non-normally distributed variables), and the $\chi^{2}$ test were used to examine relationships among the independent variables (using SPSS 15.0; SPSS, Chicago, IL, USA). Longitudinal data analysis was performed using SAS Proc Mixed for unequally spaced data, fitting the data to the SP (POW) structure (SAS Institute, Cary, NC, USA). This method fully utilises all available data points, adjusting for repeated measures, and accounts for different time intervals between measurements and different frequencies of measurements between patients. Linear regression was used to examine bivariate relationships between each independent factor and $\mathrm{HbA}_{1 \mathrm{c}}$ level, followed by multiple linear regression to identify independent effects. Results of the multivariate analysis are presented as variable estimates
( $\beta$ coefficients) that represent the change in the mean $\mathrm{HbA}_{1 \mathrm{c}}$ level for a one unit change in the independent variable, and $R^{2}$, representing the proportion of variation in $\mathrm{HbA}_{1 \mathrm{c}}$ explained by the model. Data are presented as mean \pm SD unless otherwise indicated. A $p$ value of $<0.05$ was considered statistically significant.

\section{Results}

The clinical characteristics of the study population are shown in Table 1. Participants were expected to be predominately European, followed by Pacific and Other ethnicities in numbers similar to one another and then Maori. The age at diagnosis and sex distribution was similar in all ethnic groups ( $p=0.30$ and $p=0.16$, respectively).

There were a similar number of clinic visits but some differences in duration of diabetes between ethnic groups, with Maori participants having the longest duration (4.0 years) and Other ethnicities having the shortest (3.1 years) $(p<0.001$ between groups) (Table 1). Maori and Pacific participants had higher BMI $z$ scores than Europeans, required higher insulin dosages and reported less frequent glucose self-monitoring and fewer insulin injections per day (all $p<0.001$ ). The Other group was similar to the European group in terms of BMI, insulin dosage and number of injections per day.

Table 2 demonstrates the clinical characteristics according to NZDep01 quintiles. There were no differences in age at diagnosis; however, those in quintile $\mathrm{V}$ (the most

Table 1 Clinical characteristics of the study population by ethnicity

\begin{tabular}{|c|c|c|c|c|c|c|}
\hline Characteristic & European & Maori & Pacific & Other & Total & $p$ value \\
\hline \multicolumn{7}{|l|}{ Patient details } \\
\hline$n(\%)$ & $421(75.9)$ & $31(5.6)$ & $48(8.6)$ & $55(9.9)$ & $555(100)$ & \\
\hline Sex ( $\%$ female $)$ & 47.3 & 64.5 & 43.8 & 40.0 & 47.2 & 0.16 \\
\hline $\begin{array}{l}\text { Age at diagnosis } \\
\text { (years) [range] }\end{array}$ & $\begin{array}{l}7.3 \pm 4.0 \\
{[0.5-15.6]}\end{array}$ & $\begin{array}{l}6.2 \pm 3.6 \\
{[0.5-11.8]}\end{array}$ & $\begin{array}{l}7.7 \pm 2.9 \\
{[2.3-13.4]}\end{array}$ & $\begin{array}{l}7.7 \pm 3.7 \\
{[1.8-14.6]}\end{array}$ & $\begin{array}{l}7.3 \pm 3.8 \\
{[0.5-15.6]}\end{array}$ & 0.30 \\
\hline \multicolumn{7}{|l|}{ Clinic visit details } \\
\hline Visits per patient & $11.8 \pm 8.4$ & $13.5 \pm 10.6$ & $12.1 \pm 8.4$ & $10.3 \pm 7.8$ & $11.7 \pm 8.4$ & 0.67 \\
\hline Duration (years) & $3.6 \pm 2.8^{\mathrm{a}}$ & $4.0 \pm 3.0^{\mathrm{b}}$ & $3.3 \pm 2.5^{\mathrm{c}}$ & $3.1 \pm 2.6^{\mathrm{c}}$ & $3.6 \pm 2.8$ & $<0.001$ \\
\hline BMI $z$ score & $0.7 \pm 0.8^{\mathrm{a}}$ & $1.3 \pm 0.9^{\mathrm{b}}$ & $1.3 \pm 0.7^{\mathrm{b}}$ & $0.6 \pm 0.9^{\mathrm{a}}$ & $0.8 \pm 0.9$ & $<0.001$ \\
\hline $\begin{array}{l}\text { Insulin dosage } \\
\left(\mathrm{U} \mathrm{kg}^{-1} \text { day }^{-1}\right)\end{array}$ & $0.9 \pm 0.4^{\mathrm{a}}$ & $1.1 \pm 0.4^{\mathrm{b}}$ & $1.1 \pm 0.4^{\mathrm{b}}$ & $0.9 \pm 0.4^{\mathrm{a}}$ & $0.9 \pm 0.4$ & $<0.001$ \\
\hline $\begin{array}{l}\text { Glucose self-monitoring } \\
\text { per day }\end{array}$ & $3.7 \pm 1.0^{\mathrm{a}}$ & $3.5 \pm 1.0^{\mathrm{b}}$ & $3.3 \pm 0.9^{\mathrm{c}}$ & $3.6 \pm 0.9^{b}$ & $3.7 \pm 1.0$ & $<0.001$ \\
\hline $\begin{array}{l}\text { Number of injections } \\
\text { per day }\end{array}$ & $2.2 \pm 0.5^{\mathrm{a}}$ & $2.1 \pm 0.4^{\mathrm{b}}$ & $2.0 \pm 0.3^{\mathrm{c}}$ & $2.2 \pm 0.5^{\mathrm{a}}$ & $2.2 \pm 0.5$ & $<0.001$ \\
\hline $\mathrm{HbA}_{1 \mathrm{c}}$ & $8.1 \pm 1.2^{\mathrm{a}}$ & $9.1 \pm 1.3^{\mathrm{b}}$ & $9.3 \pm 1.7^{\mathrm{c}}$ & $8.5 \pm 1.3^{\mathrm{d}}$ & $8.3 \pm 1.3$ & $<0.001$ \\
\hline $\begin{array}{l}\text { Hypoglycaemia rate } \\
\text { (per } 100 \text { patient-years) }\end{array}$ & $14.9 \pm 32.1^{\mathrm{a}}$ & $31.1 \pm 43.5^{\mathrm{b}}$ & $24.8 \pm 39.4^{\mathrm{b}}$ & $20.7 \pm 50.1^{\mathrm{a}}$ & $17.2 \pm 35.8$ & 0.03 \\
\hline
\end{tabular}

Values are expressed as mean $\pm \mathrm{SD}$ unless indicated otherwise. The $p$ value corresponds to the difference between all groups by ANOVA

$\mathrm{a}, \mathrm{b}, \mathrm{c}, \mathrm{d}$ Values within rows with different superscript letters are significantly different $(p<0.05)$ 
Table 2 Clinical characteristics of the study population by deprivation index

\begin{tabular}{|c|c|c|c|c|c|c|}
\hline NZDep01 quintile & I & II & III & IV & $\mathrm{V}$ & $p$ value \\
\hline \multicolumn{7}{|l|}{ Patient details } \\
\hline$n(\%)$ & $131(23.6)$ & $131(23.6)$ & $99(17.8)$ & $96(17.3)$ & $98(17.7)$ & \\
\hline Sex ( $\%$ female $)$ & 42.0 & 49.6 & 42.4 & 47.9 & 55.1 & 0.28 \\
\hline \multicolumn{7}{|l|}{ Clinic visit details } \\
\hline Age at diagnosis (years) & $7.3 \pm 3.8$ & $7.4 \pm 3.9$ & $7.1 \pm 4.0$ & $7.6 \pm 3.8$ & $7.0 \pm 3.6$ & 0.82 \\
\hline Visits per patient & $11.7 \pm 8.7$ & $12.3 \pm 8.6$ & $12.1 \pm 9.1$ & $11.7 \pm 8.1$ & $10.8 \pm 7.6$ & 0.83 \\
\hline Duration (years) ${ }^{\mathrm{a}}$ & $3.6 \pm 2.8$ & $3.5 \pm 2.7$ & $4.2 \pm 3.1$ & $3.2 \pm 2.3$ & $3.3 \pm 2.7$ & $<0.001$ \\
\hline BMI $z$ score $^{\mathrm{b}}$ & $0.5 \pm 0.8$ & $0.7 \pm 0.8$ & $0.8 \pm 0.9$ & $0.9 \pm 0.8$ & $1.1 \pm 0.9$ & $<0.001$ \\
\hline Insulin dosage $\mathrm{e}^{\mathrm{b}}\left(\mathrm{U} \mathrm{kg}^{-1} \mathrm{day}^{-1}\right)$ & $0.9 \pm 0.4$ & $0.9 \pm 0.4$ & $1.0 \pm 0.4$ & $1.0 \pm 0.4$ & $1.0 \pm 0.4$ & $<0.001$ \\
\hline Glucose self-monitoring per day ${ }^{\mathrm{b}}$ & $3.8 \pm 0.9$ & $3.8 \pm 1.0$ & $3.6 \pm 0.9$ & $3.4 \pm 1.1$ & $3.5 \pm 1.0$ & $<0.001$ \\
\hline Number of injections per day ${ }^{a}$ & $2.2 \pm 0.5$ & $2.2 \pm 0.6$ & $2.2 \pm 0.4$ & $2.2 \pm 0.5$ & $2.1 \pm 0.4$ & $<0.001$ \\
\hline $\mathrm{HbA}_{1 \mathrm{c}}^{\mathrm{b}}$ & $8.1 \pm 1.1$ & $8.1 \pm 1.1$ & $8.4 \pm 1.3$ & $8.4 \pm 1.5$ & $8.9 \pm 1.6$ & $<0.001$ \\
\hline $\begin{array}{l}\text { Hypoglycaemia rate } \\
\text { (per } 100 \text { patient-years) }\end{array}$ & $15.2 \pm 35.9$ & $18 \pm 41.6$ & $19.3 \pm 35.9$ & $14.7 \pm 25.7$ & $19.1 \pm 35.9$ & 0.82 \\
\hline
\end{tabular}

Values are expressed as mean $\pm \mathrm{SD}$. The $p$ values correspond to the difference between all groups ${ }^{\mathrm{a}} p \leq 0.01$ (quintile $\mathrm{V}$ vs I)

${ }^{\mathrm{b}} p<0.001$ (quintile $\mathrm{V}$ vs I)

deprived) had a slightly shorter duration of diabetes compared with those in quintile I $(p<0.001)$. BMI $z$ score increased with increasing deprivation (test for linearity $p<$ 0.001). Participants in the poorest NZDep01 quintile were on higher insulin dosages and reported less frequent glucose self-monitoring $(p<0.001)$.

Consistent with socio-demographic patterns in the general population [29], deprivation scores differed between ethnic groups (Fig. 1a, $p<0.001$ ). Disproportionately high numbers of European participants lived in households in the most advantaged areas $(29 \%$ in quintile I vs the expected 20\%), whereas $29 \%$ of Maori and $43.8 \%$ of Pacific participants lived in the most deprived $20 \%$ of areas (quintile V). Participants in the Other group were more evenly spread across quintiles.

$\mathrm{HbA}_{1 \mathrm{c}}$ level was correlated with both ethnicity and deprivation score (Fig. 1b). The mean $\mathrm{HbA}_{1 \mathrm{c}}$ value for Maori and Pacific participants was $1 \%$ and $1.2 \%$ higher than that for Europeans $(9.1 \%$ and $9.3 \%$, respectively, vs $8.1 \%, p<0.001)$; at $8.5 \%$, the value for the Other group was intermediate between the European and Maori values. Furthermore, for European, Pacific and Other ethnicities, but not Maori, the $\mathrm{HbA}_{1 \mathrm{c}}$ level was higher in participants living in the most deprived areas (quintile $\mathrm{V}$ ) compared with quintile I $(p<0.001)$.

Moderate to severe hypoglycaemia was more frequent in Maori and Pacific participants, but not different for the Other group, compared with Europeans (Table 1). There were no differences in the rate of hypoglycaemia according to deprivation score, either for the whole population or within ethnic groups (Table 2). There was a positive correlation between $\mathrm{HbA}_{1 \mathrm{c}}$ level and rate of hypoglycaemia for the cohort as a whole $(\alpha=0.115, p<0.01)$.
The following variables were significantly correlated with $\mathrm{HbA}_{1 \mathrm{c}}$ level: insulin dose $(\beta=0.80, p<0.0001)$, duration of diabetes $(\beta=0.15, p<0.0001)$, frequency of glucose self-monitoring $(\beta=-0.12, p<0.0001)$, age at clinic $(\beta=$ $0.07, p<0.0001)$, BMI $z$ score $(\beta=-0.07, p=0.02)$, female sex $(\beta=0.21, p=0.0008)$, age at diagnosis $(\beta=-0.03, p=$ $0.0004)$ and frequency of insulin injections $(\beta=0.08, p=$ 0.02 ). Age at diagnosis and number of injections were not included in the multivariate models described next, as addition of these variables to the model did not improve $R^{2}$.

In multiple regression models including ethnicity and/or deprivation index (Table 3), both factors were independently associated with $\mathrm{HbA}_{1 \mathrm{c}}$ level, but ethnicity explained slightly more of the variance in $\mathrm{HbA}_{1 \mathrm{c}}$ level than did deprivation index. In the regression involving deprivation index alone, being in quintiles III-V of SES was associated with a higher $\mathrm{HbA}_{1 \mathrm{c}}$ level, with the highest coefficient associated with the most deprived group $(\beta=0.67, p<$ 0.001). After controlling for ethnicity, being in quintile III or IV was no longer associated with a higher $\mathrm{HbA}_{1 \mathrm{c}}$ level. The association persisted for those most deprived; living in a quintile $\mathrm{V}$ household was associated with an increase in $\mathrm{HbA}_{1 \mathrm{c}}$ of $0.43 \% \quad(p<0.001)$ after adjusting for other variables. By contrast, ethnicity remained significant for all ethnic groups, irrespective of whether the model adjusted for deprivation index. However, the regression coefficients were smaller in the model including deprivation index, indicating that ethnicity and deprivation index are closely related to each other as well as to $\mathrm{HbA}_{1 \mathrm{c}}$.

Given that ethnicity and deprivation index are closely related to each other, we examined for interaction effects between ethnicity and SES. Addition of these variables resulted in a small increase in the $R^{2}$ for the final model, 
a

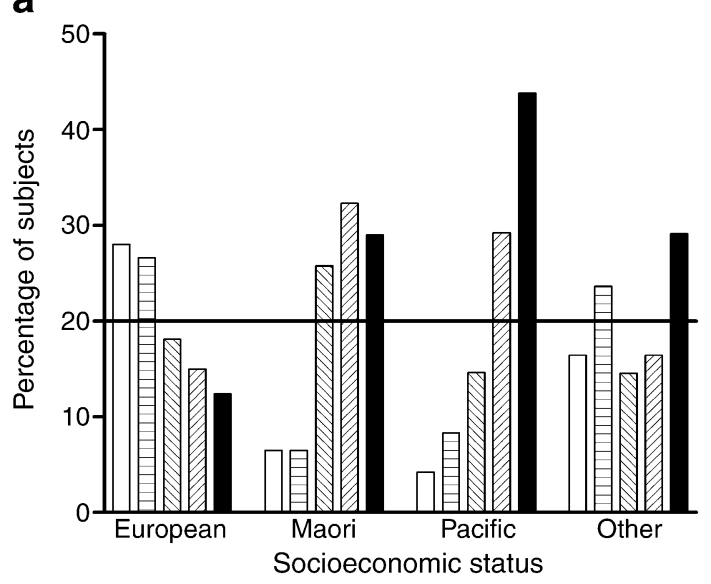

b

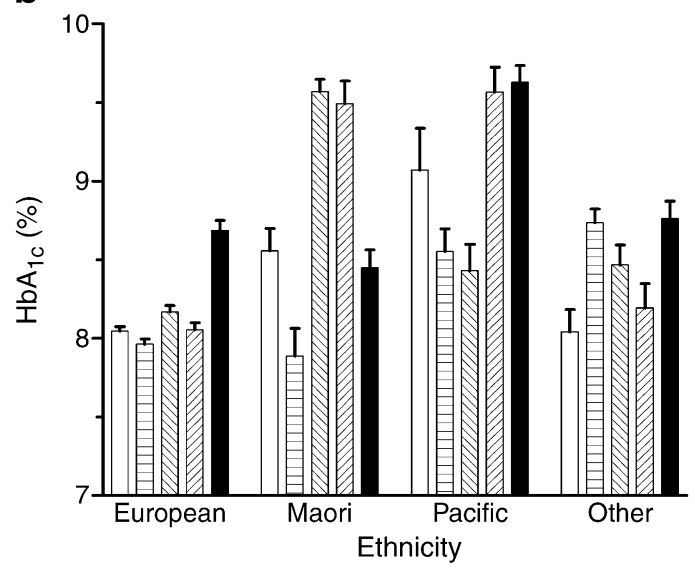

Fig. 1 Effects of ethnicity and deprivation index. a Population distribution by ethnicity and deprivation index (percentage within each ethnic group). An evenly distributed population would be expected to contain approximately $20 \%$ in each quintile. b Differences in $\mathrm{HbA}_{1 \mathrm{c}}$ according to ethnicity and deprivation index (expressed as mean $\pm \mathrm{SD}$ ). White bar, quintile I; horizontal hatched bar, quintile II; left-to-right cross-hatched bar, quintile III; right-to-left cross-hatched bar, quintile IV; black bar, quintile $\mathrm{V}$

from 0.24 to 0.26 , further demonstrating the complex interrelationship between ethnicity and SES. However, these effects were subtle and not consistent within or between different ethnic groups. For example, within the Maori group, living in a quintile IV household was significantly positively associated with an increase in $\mathrm{HbA}_{1 \mathrm{c}}(\beta=1.14)$, whereas living in a household in quintile $\mathrm{V}$ (the most deprived households), there was a non-significant and negative association with $\mathrm{HbA}_{1 \mathrm{c}}$. Similarly, there were no consistent interaction effects between ethnicity and BMI $z$ score, insulin dosage or frequency of glucose testing.

\section{Discussion}

The present study demonstrates that, in an unselected population of children and adolescents from a single centre, metabolic control was independently associated with both ethnicity and SES. Ethnicity had a greater impact than SES on $\mathrm{HbA}_{1 \mathrm{c}}$, and moderate to severe hypoglycaemia was more prevalent in minority ethnic groups and was not associated with SES. These findings are consistent with previous reports that children from ethnic minorities have higher $\mathrm{HbA}_{1 \mathrm{c}}$ levels in both the USA [2, 13, 30] and Europe $[15,16]$. However these differences have often been ascribed to differences in SES $[2,18]$. In contrast, the present analysis strongly suggests that, although part of the effect is related to higher levels of deprivation, ethnicity makes a substantial direct contribution.

Independent effects of both ethnicity and SES on health outcomes have been described in cardiovascular disease [3], cancer [31] and other chronic diseases. In New Zealand, between 1980 and 1999, mortality rates declined at all ages for the non-Maori, non-Pacific population, but showed little change among Maori and Pacific individuals, resulting in progressive widening of the gap between ethnic groups; a gap that has narrowed slightly in the early $2000 \mathrm{~s}$ [32]. Two possible hypotheses for the effect of ethnicity and SES on health outcomes have been labelled the minority poverty theory, which describes the combined disadvantage owing to ethnicity and poverty, and the diminishing returns hypothesis, which suggests that people from minority groups do not experience the same health returns for higher SES achievements [1].

The reasons for the ethnic differences seen in our study are not immediately clear. The overall mean $\mathrm{HbA}_{1 \mathrm{c}}$ level of $8.3 \%$ in this population is similar to [33], or better [34, 35] than reported in previous population samples, and levels of medical attention, as shown by rates of clinic attendance, were similar between ethnicities. BMI was highest among Maori and Pacific participants, in keeping with a previous Auckland study [36] and the results of the NCNS [24]. In turn, those in the Maori and Pacific groups required higher insulin dosages than those in the European group, raising the possibility that insulin resistance could have contributed to poorer metabolic control. However, evidence against this was provided by multivariate analysis, in which BMI $z$ score was negatively associated with $\mathrm{HbA}_{1 \mathrm{c}}$; furthermore, insulin resistance would be inconsistent with the high rates of hypoglycaemia also seen in the Maori and Pacific groups.

Although the overall reported rate of hypoglycaemia in the present study was similar to that described recently in an Australian population-based report [33], it is likely to be somewhat less, since the present analysis included episodes of moderate hypoglycaemia that were excluded by Bulsara et al. Previous studies from the DCCT [9] and others [37] found that the rate of hypoglycaemia increases with improving metabolic control. It is therefore striking that, in the present study, Maori and Pacific youth had both poor 
Table 3 Factors influencing $\mathrm{HbA}_{1 \mathrm{c}}$ : regression $\beta$ coefficients (and $p$ values) for multivariable linear regression using three different models

\begin{tabular}{llll}
\hline Variable & Model 1: all variables ${ }^{\mathrm{a}}$ & Model 2: no deprivation index $^{\mathrm{b}}$ & Model 3: no ethnicity $^{\mathrm{c}}$ \\
\hline Age at clinic & $-0.02(0.05)$ & $-0.02(0.06)$ & $-0.02(0.05)$ \\
Sex & & & $-0.09(0.14)$ \\
Male & $-0.09(0.11)$ & $-0.11(0.04)$ & Referent category \\
Female & Referent category & Referent category & $0.10(<0.001)$ \\
Duration & $0.11(<0.001)$ & $0.10(<0.001)$ & $0.71(<0.001)$ \\
Insulin dosage & $0.66(<0.001)$ & $0.67(<0.001)$ & $-0.08(<0.001)$ \\
BMI $z$ score & $-0.12(<0.001)$ & $-0.11(<0.001)$ & $-0.11(<0.001)$ \\
Glucose monitoring & $-0.11(<0.001)$ & $-0.11(<0.001)$ & \\
Ethnicity & & $0.78(<0.001)$ & $1.07(<0.001)$ \\
Maori & $0.69(<0.001)$ & $0.38(<0.001)$ & Referent category \\
Pacific & $0.94(<0.001)$ & & \\
Other & $0.32(<0.001)$ & & $0.67(<0.001)$ \\
European & Referent category & & $0.27(0.004)$ \\
Deprivation index & & & $0.26(0.005)$ \\
Quintile V & $0.43(<0.001)$ & & $0.01(0.96)$ \\
Quintile IV & $0.16(0.08)$ & & Referent category \\
Quintile III & $0.16(0.07)$ & &
\end{tabular}

${ }^{\mathrm{a}} R^{2}=0.24$

${ }^{\mathrm{b}} R^{2}=0.23$

${ }^{\mathrm{c}} R^{2}=0.20$

metabolic control and rates of hypoglycaemia that were approximately double that of European youth.

One possible mechanism for this disturbing combination would be a mismatch between insulin administration and food intake or exercise. The NCNS reported that Maori and Pacific children were less likely to eat before leaving for school in the morning and more likely to eat or drink on the way to school and to source a higher proportion of their food during school hours from outside the home [24]. We cannot address this possibility; however, it is plausible that less structured food consumption could lead to a gap between insulin administration and food intake that would predispose towards both poor metabolic control and an increased risk of hypoglycaemia.

The frequency of glucose self-monitoring was negatively associated with $\mathrm{HbA}_{1 \mathrm{c}}$ level, consistent with other studies $[38,39]$. Less frequent blood glucose monitoring was reported by both Maori and Pacific ethnicities and those in the most deprived households. Less frequent monitoring directly affects the ability to modify insulin doses appropriately and to adapt to variations in diet and exercise and could also indirectly reflect reduced adherence with the diabetes regimen overall [40]. Reduced compliance may contribute to higher insulin dosages if dosages are increased by physicians without considering missed insulin injections.

Speculatively, the independent effect of ethnicity in the present study raises the possibility that cultural barriers may have led to suboptimal communication with Maori and Pacific families [41, 42], or influenced parental ability to effectively implement suggested strategies. Strong group or family-oriented values may create a predisposition not to engage in health promotion activities when they are for the exclusive benefit of an individual, especially if these interfere with the person's obligations to the group [43]. There is some evidence that greater involvement of health workers of a similar ethnicity, or culturally targeted programmes, may improve child injury prevention [44], type 2 diabetes prevention [45] and asthma self-management [46] in adults.

Although the present study is strengthened by its relatively large sample size and prospective data collection, several limitations should be considered. The sample is predominantly European, reflecting the worldwide predominance of Europeans with type 1 diabetes. However, this may limit our ability to identify factors that are only of significance in the smaller ethnic groups. No data on family composition or cohesiveness, which likely mediate some of the effects of ethnicity and deprivation on metabolic control, were collected $[13,19,47]$. Since hypoglycaemia was a rare event the confidence intervals are broad and rates can be affected by recall bias. However, bias is likely to be minimal given that data were collected every 3 months. Our measure of ethnicity reflects cultural identity rather than genetic background, which may influence diabetes expression. Furthermore, approximately $10 \%$ of New Zealanders identify with more than one ethnic group [20], with higher rates among younger age groups as a result of ethnic intermarriage. Prioritised ethnicity, as used in the present study, reduces ethnic diversity and may conceal differences 
between those identifying with more than one ethnicity and the prioritised group [48]. Similarly, NZDep01 indices apply to areas rather than individual households, and some families, particularly those from smaller minority groups, may choose to live in communities based on ethnicity rather than socioeconomic factors. However, NZDep01 has relatively fine granularity and correlates consistently with individual health outcomes [49]. It should be noted that these issues would be likely to minimise, not increase, differences between groups in the present study.

Finally, in the current study, data were collected over more than a decade, coinciding with the introduction of analogue insulins, increased emphasis on glucose selfmonitoring and stricter glycaemic targets. Despite these therapeutic changes, there was no change in mean $\mathrm{HbA}_{1 \mathrm{c}}$ over time ( $p=0.09$, data not shown), with the clinic mean $\mathrm{HbA}_{1 \mathrm{c}}$ varying from $8.1 \%$ (1995) to $8.5 \%$ (1996 and 2003). This may be related to factors such as the almost doubling of patient numbers and increasing patient age (mean 9.0 years in 1995 to 10.3 years in $2005, p<0.001$ ).

In conclusion, this study suggests that Maori and Pacific children with type 1 diabetes are at greater risk of poor glycaemic control and that this risk is related, but not solely due to SES. The apparently independent effects of ethnicity over and above SES have important implications for diabetes care and suggest that standard diabetes practice is not optimal for some cultures. Given the association between $\mathrm{HbA}_{1 \mathrm{c}}$ and the risk of long-term complications, further research to understand and improve these ethnic disparities is of great importance.

Acknowledgements A Southern Trusts Research Fellowship awarded to P. J. Carter supported this study. We are grateful to C. Hira for database design, Novo Nordisk and Sanofi-Aventis for their financial support of the database, the diabetes nurse specialists, R. Hornung, J.-A. Holt, G. Harris, R. Dowd and S. Tregurtha, who assisted in data collection and J. Biggs and D. Rowe for assistance with data entry.

Duality of interest The authors declare that there is no duality of interest associated with this manuscript.

\section{References}

1. Farmer MM, Ferraro KF (2005) Are racial disparities in health conditional on socioeconomic status. Soc Sci Med 60:191-204

2. Gallegos-Macias AR, Macias SR, Kaufman E, Skipper B, Kalishman N (2003) Relationship between glycemic control, ethnicity and socioeconomic status in Hispanic and white non-Hispanic youths with type 1 diabetes mellitus. Pediatric Diabetes 4:19-23

3. Cooper RS (2001) Social inequality, ethnicity and cardiovascular disease. Int J Epidemiol 30:S48-S52

4. Wen M (2007) Racial and ethnic differences in general health status and limiting health conditions among American children: parental reports in the 1999 national survey of America's families. Ethn Health 12:401-422
5. Nazroo J, Jackson J, Karlsen S, Torres M (2007) The Black diaspora and health inequalities in the US and England: does where you go and how you get there make a difference. Sociol Health Illn 29:811-830

6. Harris R, Tobias M, Jeffreys M, Waldegrave K, Karlsen S, Nazroo $\mathrm{J}$ (2006) Effects of self-reported racial discrimination and deprivation on Maori health and inequalities in New Zealand: cross-sectional study. Lancet 367:2005-2009

7. Blakely T, Fawcett J, Hunt D, Wilson N (2006) What is the contribution of smoking and socioeconomic position to ethnic inequalities in mortality in New Zealand. Lancet 368:44-52

8. Diabetes Control and Complications Trial Research Group (1993) The effect of intensive treatment of diabetes on the development and progression of long-term complications in insulin-dependent diabetes mellitus. N Engl J Med 329:977-986

9. Diabetes Control and Complications Trial Research Group (1994) Effect of intensive diabetes treatment on the development and progression of long-term complications in adolescents with insulin-dependent diabetes mellitus: Diabetes Control and Complications Trial. J Pediatr 125:177-188

10. Diabetes Control and Complications Trial Research Group (2002) Effect of intensive therapy on the microvascular complications of type 1 diabetes mellitus. JAMA 287:2563-2569

11. White NH, Cleary PA, Dahms W, Goldstein D, Malone J, Tamborlane WV (2001) Beneficial effects of intensive therapy of diabetes during adolescence: outcomes after the conclusion of the Diabetes Control and Complications Trial (DCCT). J Pediatr 139:804-812

12. Dabadghao P, Vidmar S, Cameron FJ (2001) Deteriorating diabetic control through adolescence-do the origins lie in childhood. Diabet Med 18:889-894

13. Auslander WF, Thompson S, Dreitzer D, White NH, Santiago JV (1997) Disparity in glycemic control and adherence between African-American and Caucasian youths with diabetes. Family and community contexts. Diabetes Care 20:1569-1575

14. Delamater AM, Shaw KH, Applegate EB et al (1999) Risk for metabolic control problems in minority youth with diabetes. Diabetes Care 22:700-705

15. Hoey H, Aanstoot HJ, Chiarelli F et al (2001) Good metabolic control is associated with better quality of life in 2,101 adolescents with type 1 diabetes. Diabetes Care 24:1923-1928

16. Povlsen L, Olsen B, Ladelund S (2005) Diabetes in children and adolescents from ethnic minorities: barriers to education, treatment and good metabolic control. J Adv Nurs 50:576-582

17. Chalew SA, Gomez R, Butler A et al (2000) Predictors of glycemic control in children with type 1 diabetes: the importance of race. J Diabetes its Complicat 14:71-77

18. Springer D, Dziura J, Tamborlane WV et al (2006) Optimal control of type 1 diabetes mellitus in youth receiving intensive treatment. J Pediatr 149:227-232

19. Swift EE, Chen R, Hershberger A, Holmes CS (2006) Demographic risk factors, mediators, and moderators in youths' diabetes metabolic control. Ann Behav Med 32:39-49

20. Statistics New Zealand (2007) 2006 Census of population and dwellings. Available from http://www.stats.govt.nz/census/2006census-data/regional-summary-tables.htm, accessed 24 April 2007

21. Campbell-Stokes PL, Taylor BJ, New Zealand Children's Diabetes Working Group (2005) Prospective incidence study of diabetes mellitus in New Zealand children aged 0 to 14 years. Diabetologia 48:643-648

22. Blakely T, Tobias M, Robson B, Ajwani S, Bonne M, Woodward A (2005) Widening ethnic mortality disparities in New Zealand 1981-99. Soc Sci Med (1982) 61:2233-2251

23. Jamieson LM, Koopu PI (2007) Associations between ethnicity and child health factors in New Zealand. Ethn Dis 17:84-91

24. Parnell W, Scragg R, Wilson N, Schaaf D, Fitzgerald E (2003) NZ food NZ children: key results of the 2002 National Children's Nutrition Survey. Ministry of Health, Wellington 
25. Douglas NM, Dockerty JD (2007) Survival by ethnicity for children diagnosed with cancer in New Zealand during 19901993. J Paediatr Child Health 43:173-177

26. Salmond C, Crampton P (2002) NZDep2001 index of deprivation user's manual. Department of Public Health, Wellington School of Medicine and Health Sciences, Wellington

27. Centers for Disease Control and Prevention (2005) A SAS programme for the CDC growth charts. Available from http:// www.cdc.gov/nccdphp/dnpa/growthcharts/resources/sas.htm, accessed 20 April 2007

28. Australasian Paediatric Endocrine Group (2005) Clinical practice guidelines: type 1 diabetes in children and adolescents. National Health and Medical Research Council, Canberra

29. Auckland District Health Board (2007) Auckland DHB, domicile population and statistics. Available from http://www.adhb.govt.nz/ about/population_stats.htm, accessed 10 September 2007

30. Delamater AM, Albrecht DR, Postellon DC, Gutai JP (1991) Racial differences in metabolic control of children and adolescents with type I diabetes mellitus. Diabetes Care 14:20-25

31. Chu KC, Miller BA, Springfield SA (2007) Measures of racial/ ethnic health disparities in cancer mortality rates and the influence of socioeconomic status. J Natl Med Assoc 99:1092-1100 11021104

32. Blakely T, Tobias M, Atkinson J, Yeh LC, Huang K (2007) Tracking disparity: trends in ethnic and socioeconomic inequalities in mortality, 1981-2004. Ministry of Health, Wellington

33. Bulsara MK, Holman CD, Davis EA, Jones TW (2004) The impact of a decade of changing treatment on rates of severe hypoglycemia in a population-based cohort of children with type 1 diabetes. Diabetes Care 27:2293-2298

34. Cardwell CR, Patterson CC, Allen M, Carson DJ, Northern Ireland Paediatric Diabetes Study G (2005) Diabetes care provision and glycaemic control in Northern Ireland: a UK regional audit. Arch Dis Childhood 90:468-473

35. Scottish Study Group for the Care of the Young Diabetic (2001) Factors influencing glycemic control in young people with type 1 diabetes in Scotland: a population-based study (DIABAUD2). Diabetes Care 24:239-244

36. Tyrrell VJ, Richards GE, Hofman P, Gillies GF, Robinson E, Cutfield WS (2001) Obesity in Auckland school children: a comparison of the body mass index and percentage body fat as the diagnostic criterion. Int J Obes Relat Metab Disord 25:164-169
37. Chase HP, Lockspeiser T, Peery B et al (2001) The impact of the Diabetes Control and Complications Trial and Humalog insulin on glycohemoglobin levels and severe hypoglycemia in type 1 diabetes. Diabetes Care 24:430-434

38. Dorchy H, Roggemans MP, Willems D (1997) Glycated hemoglobin and related factors in diabetic children and adolescents under 18 years of age: a Belgian experience. Diabetes Care 20:2-6

39. Levine BS, Anderson BJ, Butler DA, Antisdel JE, Brackett J, Laffel LM (2001) Predictors of glycemic control and short-term adverse outcomes in youth with type 1 diabetes. J Pediatr 139:197-203

40. Harris MA, Wysocki T, Sadler M et al (2000) Validation of a structured interview for the assessment of diabetes self-management. Diabetes Care 23:1301-1304

41. Tobias M, Yeh LC (2007) How much does health care contribute to health inequality in New Zealand. Aust N Z J Public Health 31:207-210

42. Barwick H (2000) Improving access to primary care for Maori and Pacific peoples. A literature review commissioned by the Health Funding Authority. Ministry of Health, Wellington

43. Garcia A (2006) Is health promotion relevant across cultures and the socioeconomic spectrum. Fam Commun Health 29:20S-27S

44. Brewin M, Coggan C (2002) Evaluation of a New Zealand indigenous community injury prevention project. Injury Control and Safety Promotion 9:83-88

45. McAuley KA, Murphy E, McLay RT et al (2003) Implementation of a successful lifestyle intervention programme for New Zealand Maori to reduce the risk of type 2 diabetes and cardiovascular disease. Asia Pac J Clin Nutr 12:423-426

46. Ratima MM, Fox C, Fox B et al (1999) Long-term benefits for Maori of an asthma self-management program in a Maori community which takes a partnership approach. Aust N Z J Public Health 23:601-605

47. Urbach SL, LaFranchi S, Lambert L, Lapidus JA, Daneman D, Becker TM (2005) Predictors of glucose control in children and adolescents with type 1 diabetes mellitus. Pediatr Diabetes 6:69-74

48. Statistics New Zealand (2006) The impact of prioritisation on the interpretation of ethnicity data. Available from http://www.stats. govt.nz/NR/rdonlyres/8C3DACBC-5E9F-4BC7-8F2B$\mathrm{BD} 5311961008 / 0 /$ TheImpactofPrioritisationontheInterpretation ofEthnicity.pdf, accessed 13 March 2007

49. Salmond C, Crampton P (2001) NZDep96-What does it measure. Soc Policy J N Z 17:82-100 